\title{
PrEP: AIDS-Free Hope in Namibia?
}

\author{
Eben-Eser Ndaamenwa Namhindo ${ }^{{ }^{*}}$, Fanghua $\mathrm{Mei}^{i^{*}}$, Rui $\mathrm{Cao}^{3}$, Shenghai $\mathrm{Lai}^{4}$, Yufan $\mathrm{Dai}^{5}$, Hong Lai ${ }^{4}$, Meng \\ $\mathrm{Zhu}^{1,6}$, Huimin $\mathrm{Fu}^{1,6}$, Huang Huang ${ }^{1,6,7}$ \& Jun Wang ${ }^{1,6}$
}

${ }^{1}$ Department of Pharmacology, Bioengineering and Food College, Hubei University of Technology, Wuhan, Hubei 430068, China

${ }^{2}$ Hubei Provincial Center for Disease Control and Prevention; Hubei Provincial Academy of Prevention Medicine, Wuhan, Hubei 430072, China

${ }^{3}$ Department of Chemistry, Johns Hopkins University, Baltimore, MD 21218, USA

${ }^{4}$ Department of Radiology, Johns Hopkins University School of Medicine, Baltimore, MD 21287, USA

${ }^{5}$ Department of Physics, Wuhan University, Wuhan, Hubei 430072, China

${ }^{6}$ National 111 Center for Cellular Regulation and Molecular Pharmaceutics, Wuhan, Hubei 430068, China

${ }^{7}$ Huazhong Agricultural University, Wuhan, Hubei 430070, China

*These two authors contributed equally to this paper

Correspondence: Huang Huang, Department of Pharmacology, Bioengineering and Food College, Hubei University of Technology, Huazhong Agricultural University. E-mail: 15338608@qq.com;

Jun Wang, Department of Pharmacology, Bioengineering and Food College, Hubei University of Technology. E-mail: jun_wang@hbut.edu.cn

Received: December 10, 2016

Accepted: December 15, 2016 Online Published: December 21, 2017

doi:10.5539/ijb.v10n1p13

URL: https://doi.org/10.5539/ijb.v10n1p13

\begin{abstract}
Human immunodeficiency virus (HIV) is a lentivirus that causes infections and over time leads to acquired immunodeficiency syndrome (AIDS). HIV causes a loss of immune function in human and subsequent development of opportunistic infections. Namibia, one important country in West Africa, has been suffering HIV/AIDS incidence over years. Among people between 15 to 49 years old, the national HIV prevalence rate is more than $10 \%$, which causes huge health and economic loss. Recently, Pre-exposure prophylaxis (PrEP) has been approved in Namibia for better prevention of HIV/AIDS. In this paper, we will review the current epidemic condition of HIV and the role played by PrEP in Namibia.
\end{abstract}

Keywords: HIV, AIDS, PrEP, Namibia

\section{Background of HIV and AIDS}

It has been widely accepted that human immunodeficiency virus (HIV) originated in the Democratic Republic of Congo in 1920s when chimpanzees passed this virus to humans (Faria et al., 2014). In 1980s, a number of rare infection cases were reported worldwide to relate to this virus, including the United States and Europe. For the first time, Centers for Disease Control and Prevention (CDC) used the term 'AIDS' (acquired immune deficiency syndrome) to describe this disease (Centers for Disease Control and Prevention (CDC) \& United States of America, 1987). Along prevalence of HIV, researchers have been study what it is, how it is transmitted, what to stop it and whether there is a vaccine (Callaghan, Ford, \& Schneider, 2010).

HIV is a lentivirus. It contains gp 120 protein around it, p24 protein inside it and viral RNA (Chinen \& Shearer, 2002). When HIV attacks human cells, first gp 120 attaches to CD4+ receptors of T lymphocytes. Then HIV enters the cell and makes viral DNA. Afterwards, the enslaved host cell produces new viruses that bud, which destroy the host cell's membrane, causes cellular death and allowing the virus to leave to attack other CD4+ lymphocyte cells (Figure 1) (Åkerblom et al., 1990). 


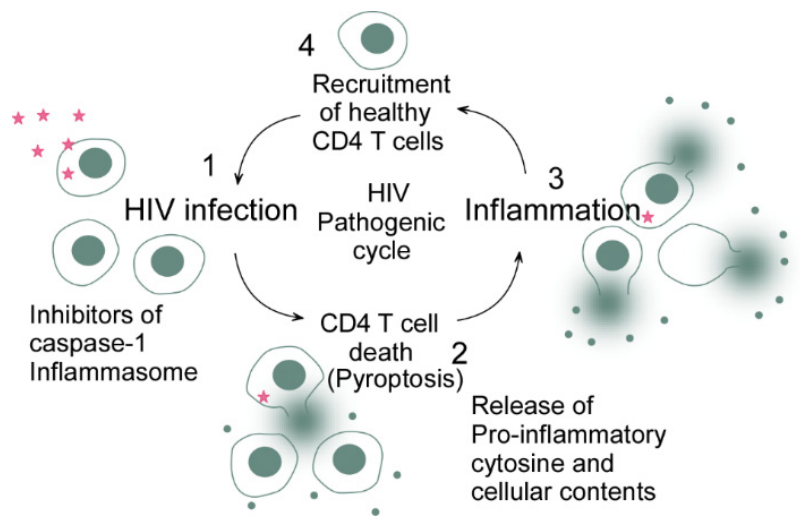

Figure 1. Pathogenic cycle of HIV

\section{Prevalence of HIV in Namibia}

HIV/AIDS is still the number one killer in Namibia. About 3900 people died each year due to AIDS. Around 14,000 newly infected cases were identified each year (Page et al., 1990; Fischl et al., 1992; Brown, Sorrell, \& Raffaelli, 2005; Susser \& Stein, 2000). Among people between 15 to 49 years old, the national HIV prevalence rate stays at $13.3 \%$. Based on the official Demographic and Health Survey by Namibia government in 2014, northern regions of Namibia are the most affected by HIV/AIDS, particularly with high rates at Zambezi (23.7\%), Omusati (17.4\%), Kavango (17\%), Oshana (16.1\%), and Ohangwena (15.6\%) (Khumalo, McKay, \& Freimund, 2015).

A few factors contribute to the high prevalence or incidence of HIV in Namibia. Multiple and concurrent partnerships and intergenerational sex are the major driver for the HIV epidemic. Alcohol abuse, lack of sex protection and high population mobility are listed as the other factors (Lane et al., 2011). In 1990s, HIV/AIDS incidence began to drop, due to tremendous progress for HIV/AIDS response by Namibia government. However, the decline rate is levelling off and the epidemic trend hasn't been stopped. Namibian people have the motivation for a better life and cross-country collaboration in economy and medicine are not approachable than before. PrEP is a newly approved strategy by Namibia to tackle HIV incidence.

\section{What is PrEP?}

Pre-exposure prophylaxis (or PrEP) is the preventative strategy for people to take HIV medicines daily to reduce the risk of HIV infection (Ware et al., 2012). Studies have shown that PrEP is powerful in preventing HIV among high-risk population (Karim, Kashuba, Werner, \& Karim, 2011; McCormack et al., 2016). World Health Organization (WHO) has highly recommended PrEP in different countries (See Figure 1) and it has been widely accepted in the United States for HIV prevention.

PrEP is neither a vaccine, or functioning the same way as vaccine. Vaccine helps human body generate antibody and fight off infection for years. It rarely needs a daily intake. PrEP requires a daily oral intake of a medical pill, which is a combination of two drugs (tenofovir and emtricitabine). This pill helps block HIV virus.

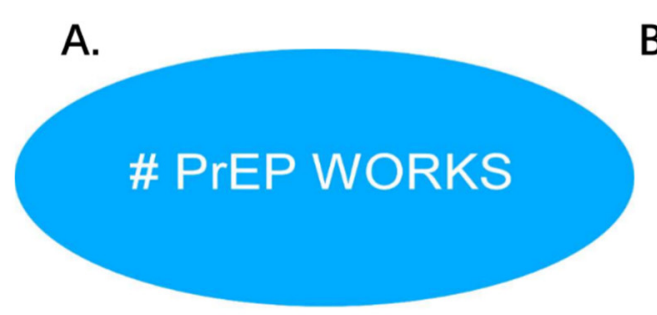

The time for debate on the effectiveness of PrEP is over.

B.

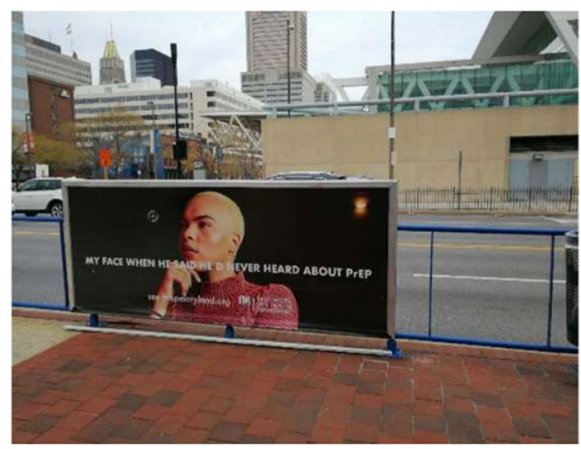

Figure 2. (A) the sign of PrEP to fight off HIV. (2) street advertisement of PrEP in Baltimore downtown, Maryland, USA 


\section{What impact would PrEP bring to Namibia?}

In May 2017, PrEP was approved the Namibia Medicines Regulatory Council (NMRC), in order to reduce HIV infection during groups, who are either sexually active HIV-negative person, or have history of high-risk sexual activities such as no condom use or inconsistent use. NMRC approved two antiretroviral drugs, namely TDF (tenofovir) and FTC (emtricitabine), for PrEP. If these medications are used correctly, infection rate can be reduced to $90 \%$ or even higher (Anderson et al., 2012).

As proved by research in the United States and Europe, PrEP is so far the most powerful method to reduce the risk of HIV infection (ref). In Namibia, PrEP will be used as part of the prevention package for HIV (Cohen et al., 2011), which includes: (1) HIV testing service, (2) ART (anti-retroviral therapy), (3) STI (sexual transmission infection) prevention, voluntary medical male circumcision, (4) male and female condoms, and (5) lubricants.

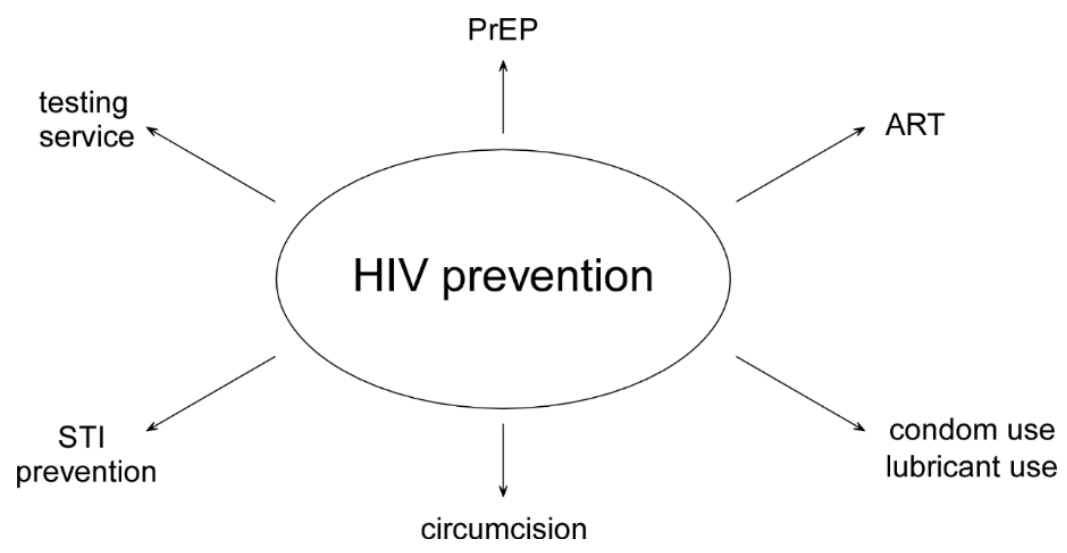

Figure 3. The prevention package for HIV.

\section{Conclusion and Future Direction}

PrEP is a long-term commitment, which needs to be taken daily to be effective. Side effect is another concern, such as nausea and vomiting, though it has shown to last long in practice. Cost is another factor to consider. Someone on the generic version of medication spends around $\mathrm{N} \$ 220$ per month. If the brand medication is used, it costs about $\mathrm{N} \$ 500$, which remains much cheaper than treatment.

In summary, PrEP opens the door for "Start free, Stay free, AIDS free" to end AIDS among children, adolescents and young women in Namibia, and it needs plenty of hard work, collaboration, support from Namibian government and the international community.

\section{References}

Åkerblom, L., Hinkula, J., Broliden, P. A., Mäkitalo, B., Fridberger, T., Rosen, J., ... \& Wahren, B. (1990). Neutralizing cross-reactive and non-neutralizing monoclonal antibodies to HIV-1 gp 120. Aids, 4(10), 953-960. Retrieved from http://journals.lww.com/aidsonline/toc/1990/10000

Anderson, P. L., Glidden, D. V., Liu, A., Buchbinder, S., Lama, J. R., Guanira, J. V., ... iPrEx Study Team. (2012). Emtricitabine-Tenofovir Concentrations and Pre-Exposure Prophylaxis Efficacy in Men Who Have Sex with Men. Science Translational Medicine, 4, 125-138. Https://doi.org/10.1126/scitranslmed.3004006

Brown, J., Sorrell, J., \& Raffaelli, M. (2005). An exploratory study of constructions of masculinity, sexuality and HIV/AIDS in Namibia, Southern Africa. Culture, health \& sexuality, 7(6), 585-598. https://doi.org/10.1080/ 13691050500250198

Callaghan, M., Ford, N., \& Schneider, H. (2010). A systematic review of task-shifting for HIV treatment and care in Africa. Human resources for health, 8(1), 8-16. Https://doi.org/10.1186/1478-4491-8-8

Centers for Disease Control and Prevention (CDC), \& United States of America. (1987). Revision of the Centers for Disease Control (CDC) Surveillance Case Definition for Acquired Immunodeficiency Syndrome. Morbidity and Mortality Weekly Report, 36(1S), 3S-15S. Retrieved from https://www.cdc.gov/mmwr/ preview/mmwrhtml/rr6303a1.htm 
Chinen, J., \& Shearer, W. T. (2002). Molecular virology and immunology of HIV infection. Journal of Allergy and Clinical Immunology, 110(2), 189-198. Https://doi.org/http://dx.doi.org/10.1067/mai.2002.126226

Cohen, M. S., Chen, Y. Q., McCauley, M., Gamble, T., Hosseinipour, M. C., Kumarasamy, N., ... \& Godbole, S. V. (2011). Prevention of HIV-1 infection with early antiretroviral therapy. New England journal of medicine, 365(6), 493-505. Https://doi.org/10.1056/NEJMoa1105243

Faria, N. R., Rambaut, A., Suchard, M. A., Baele, G., Bedford, T., Ward, M. J., ... \& Posada, D. (2014). The early spread and epidemic ignition of HIV-1 in human populations. Science, 346(6205), 56-61. https://doi.org/10. 1126/science. 1256739

Fischl, M. A., Daikos, G. L., Uttamchandani, R. B., Poblete, R. B., Moreno, J. N., Reyes, R. R., ... \& Saldana, M. J. (1992). Clinical presentation and outcome of patients with HIV infection and tuberculosis caused by multiple-drug-resistant bacilli. Annals of Internal Medicine, 117(3), 184-190. Https://doi.org/10.7326/0003 $-4819-117-3-184$

Karim, S. S. A., Kashuba, A. D., Werner, L., \& Karim, Q. A. (2011). Drug concentrations after topical and oral antiretroviral pre-exposure prophylaxis: implications for HIV prevention in women. Lancet, 378(9787), 279281. Https://doi.org/10.1016/S0140-6736(11)60878-7.

Khumalo, K. E., McKay, K. H., \& Freimund, W. (2015, February). Who is a "real woman"? Empowerment and the discourse of respectability in Namibia's Zambezi region. In Women's Studies International Forum, 48, 47-56. https://doi.org/10.1016/j.wsif.2014.10.002

Lane, T., Raymond, H. F., Dladla, S., Rasethe, J., Struthers, H., McFarland, W., \& McIntyre, J. (2011). High HIV prevalence among men who have sex with men in Soweto, South Africa: results from the Soweto Men's Study. AIDS and Behavior, 15(3), 626-634. Https://doi.org/10.1007/s10461-009-9598-y

McCormack, S., Dunn, D. T., Desai, M., Dolling, D. I., Gafos, M., Gilson, R., ... \& Mackie, N. (2016). Pre-exposure prophylaxis to prevent the acquisition of HIV-1 infection (PROUD): effectiveness results from the pilot phase of a pragmatic open-label randomised trial. The Lancet, 387(10013), 53-60. http://dx.doi.org/10.1016/S0140-6736(15)00056-2

Page, J. B., Lai, S., Chitwood, D. D., Klimas, N. G., Smith, P. A., \& Fletcher, M. A. (1990). HTLV-I/II seropositivity and death from AIDS among HIV-1 seropositive intravenous drug users. The Lancet, 335(8703), 1439-1441. http://dx.doi.org/10.1016/0140-6736(90)91456-K

Susser, I., \& Stein, Z. (2000). Culture, sexuality, and women's agency in the prevention of HIV/AIDS in southern Africa. American Journal of Public Health, 90(7), 1042-1048. Retrieved from https://www.ncbi.nlm.nih.gov/pmc/articles/PMC1446308/pdf/10897180.pdf

Ware, N. C., Wyatt, M. A., Haberer, J. E., Baeten, J. M., Kintu, A., Psaros, C., ... \& Bangsberg, D. R. (2012). What's love got to do with it? Explaining adherence to oral antiretroviral pre-exposure prophylaxis (PrEP) for HIV serodiscordant couples. Journal of acquired immune deficiency syndromes (1999), 59(5). Https://doi.org/10.1097/QAI.0b013e31824a060b.

\section{Copyrights}

Copyright for this article is retained by the author(s), with first publication rights granted to the journal.

This is an open-access article distributed under the terms and conditions of the Creative Commons Attribution license (http://creativecommons.org/licenses/by/4.0/). 